\title{
HUMAN BREAST MILK FORTIFICATION WITH SKIMMED MILK AND OLIVE OIL FOR WEIGHT GAIN IN VERY LOW BIRTH WEIGHT NEONATES
}

\author{
Arouj Waqqas, Zeeshan Ahmed*, Huma Farrukh, Hina Khalid**, Talal Waqar** \\ Combined Military Hospital Lahore/National University of Medical Sciences (NUMS) Pakistan, *Pak Emirates Military Hospital/National University of Medical \\ Sciences (NUMS) Rawalpindi Pakistan, ${ }^{* *} \mathrm{CMH}$ Lahore Medical College, Lahore/National University of Medical Sciences (NUMS) Pakistan
}

\section{ABSTRACT}

Objective: To observe the effect of fortification of expressed human breast milk with olive oil and skimmed milk in improving weight gain in very low birth weight neonates and shortening their length of hospital stay.

Study Design: A comparative prospective study.

Place and Duration of Study: Combined Military Hospital Lahore, from Mar 2018 to Mar 2019.

Methodology: Neonates admitted with very low birth weight and gestational age of $<34$ weeks were included in study. Sixty babies were enrolled using non-probability consecutive sampling; random number table used to allocate them into a fortifycation group and a control group. The control group received expressed milk alone, while olive oil oneml twice daily and skimmed milk one gram in every third feed were added to expressed milk in the fortification group.

Results: The study comprised of 60 neonates, with 30 in each of the groups. Weight gain was $24.83 \pm 5.63$ in the fortification group and $11.72 \pm 3.95$ in the control group $(p \leq 0.001)$. Mean hospital stay was $20.57 \pm 16.511$ in the fortification group and $27.67 \pm 8.89$ in the control group $(p \leq 0.043)$.

Conclusion: Olive oil and skimmed milk fortification of breast milk was effective for weight gain and reducing length of hospital stay in very low birth weight neonates.

Keywords: Expressed breast milk, Fortification, neonate, Olive oil, Skimmed milk, Very low birth weight, Weight gain.

This is an Open Access article distributed under the terms of the Creative Commons Attribution License (https://creativecommons.org/licenses/by-nc/4.0/), which permits unrestricted use, distribution, and reproduction in any medium, provided the original work is properly cited.

\section{INTRODUCTION}

Very low birth weight (VLBW) is an infant with aweight of $<1500$ grams at birth; this is regardless of gestational age. VLBW infants are further categorized into three: Appropriate for gestational age (AGA) preterm (born <37 week of completed gestation), small for gestational age (SGA) and intrauterine growth restricted (IUGR) babies (both $<10$ thcentile) ${ }^{1}$. Each year, 20 million infants are born with low birth weight. Developing countries contribute to $92 \%$ of low birth weight infants, $70 \%$ in Asia and 22\% in Africa ${ }^{2}$. In Pakistan, it is estimated that $22 \%$ babies are low birth weight at birth $^{3}$. The main factors associated with VLBW are prematurity, maternal nutritional status, socio-economic factors, maternal age, maternal anemia, antepartum hemor-rhage, pregnancy induced hypertension and urinary tract infections ${ }^{4}$.

Infants with very low birth weight tend to have high mortality. Globally $60-80 \%$ of all neonatal deaths are attributed to low birth weight mostly VLBW preterm or SG Ainfants 5 . The ones who survive are likely to experience both immediate and long term comorbidities. Not only they have increased incidence of complications like necrotizing enterocolitis (NEC), Inter-

Correspondence: Dr Arouj Waqqas, Department of Neonatal Medicine, Combined Military Hospital, Lahore Pakistan

Received: 09 May 2020; revised received: 08 Oct 2020; accepted: 21 Oct 2020 ventricular hemorrhage (IVH) and Respiratory distress syndrome (RDS) but also suffer from poor growth, learning difficulties and low IQ latter in life ${ }^{6}$. Viable solutions are needed to avoid these problems.

Early and adequate nutrition is one of the key factorsthat can alter overall outcome of these infants. Optimum nutrition in early days after birth results in better neurodevelopmental outcomes and also reduces the need for accelerated catchup growth, thus minimizing the risk for developing metabolic syndrome in their adulthood 7 .

Worldwide, consensus is that infants with VLBW must be provided with adequate nutrition immediately after birth. Enteral feeding is preferred over parenteral nutrition due to hazards of intravenous lines and increased risk of sepsis ${ }^{8}$. Breast milk is the ideal nutrition and considered the gold standard for VLBW infants as it contains numerous beneficial nutrients, anti inflammatory and immune boosting properties which promotes growth and reduces number of complications like NEC and sepsis in these infants ${ }^{9}$. However, VLBW infants need extra nutrition and calories for optimal growth, which breast milk alone cannot provide. Fortification with proteins, phosphate and calcium is required to fulfill all requirements ${ }^{10}$.

Human milk fortifiers, which contain the additional calories and extra nutrition required by these 
infants, have been routinely used in neonatal ICUs in resource rich settings. Although recently available in Pakistan, they are expensive, and not readily available. A resource poor setting in a developing country like Pakistan needs a more practical solution. In this study, we examined the addition of easy to afford olive oil and skimmed milk to expressed breast milk (EBM) thus, adding proteins and calories, to accelerate the increase in weight gain. We also proposed to see if this would decrease the length of hospital stay (LOS), enabling earlier discharge of VLBW preterm infants.

\section{METHODOLOGY}

This was acomparative prospective study, carried at the department of Neonatology, Combined Military Hospital $(\mathrm{CMH})$, Lahore. The study was approved by the Research and Ethics Board of CMH Lahore Medical College (reference no. 467/ERC/CMHLMC, dated 1603-2020). The study was conducted from March 2018 to March 2019. A sample size of 60 cases (30 in each group) was calculated using $95 \%$ confidence interval and $80 \%$ power of test and taking expected mean hospital stay was $28.29 \pm 12.28$ in interventional group and $20.33 \pm 8.7617$. Infants with VLBW < 1500 grams and gestational age of $<34$ weeks whentolerating feeds of $100 \mathrm{ml} / \mathrm{kg} /$ day were included in study. Exclusion criteria were infants with chromosomal anomalies, surgical problems, majorcardiac disease and NEC stage 3. The sampling technique used was consecutive nonprobability sampling. Infants were randomized into two groupsby using therandom number table. After taking written informed consent from parents, 60 cases were enrolled in the study; 30 were randomized to the fortification group (olive oil and skimmed milk added to expressed breast milk) and the remaining 30 were randomized to the control group (only expressed breast milk).

Babies in the fortification group received expressed breast milk every 2 hours. Feeds were increased daily at a rate of $20 \mathrm{ml} / \mathrm{kg} /$ day to a maximum of 180 $\mathrm{ml} / \mathrm{kg} /$ day along with one gram of skimmed milk in 4 feeds per day and $1 \mathrm{ml}$ of olive oil was added in two feeds per day. Onegram skimmed milk provides 0.45 gram protein and $1 \mathrm{ml}$ of olive oil provides approximately $9 \mathrm{kcal}$. Thus 1.8 gms additional proteins, $2 \mathrm{gm}$ fats and a total of $25 \mathrm{kcal}$ were added as fortification to EBM. Babies in control group received only expressed breast milk every 2 hours. Feeds were advanced at a rate of $20 \mathrm{ml} / \mathrm{kg} /$ day to a maximum of $180 \mathrm{ml} / \mathrm{kg} /$ day. Feeds in both groups were given through Oro gastric tube feeding till 34 weeks of corrected gestation or till the baby was able to suck.

Basic demographic data were collected using a predesigned performamade by the neonatal intensive care team. All neonates were weighed daily, whichwas measured in grams by a calibrated electronic weighing scale (kinlee EBSL-20) with error margin of $\pm 5 \mathrm{~g}$. Blood urea nitrogen and creatinine were monitored once a week. Head circumference and length were measured weekly in $\mathrm{cm}$ by a non-stretchable measuring tape. Infants were monitored for side effects such as feed intolerance which was defined as $>50 \%$ residual feed in oro gastric tube aspirate in two consecutive feeds. All parameters were measured until the time of discharge.

Neonates in both the groups were kept in neutral thermal environment and received multivitamins, Iron, calcium and vitamin D supplementation as per NICU protocol as well as kangaroo mother care (KMC) daily for 8 hours was provided to all neonates.

All the data wereentered into the statistical package for social sciences (SPSS) version 20 and analyzed. Mean and standard deviation was calculated for quantitative data like age and gestational age and frequency and percentages were calculated for qualitative data like gender. Both groups were compared using independent $\mathrm{t}$-test for weight gain, gain in length and head circumference and length of hospital stay $p$-value $\leq 0.05$ wasconsidered as significant.

\section{RESULTS}

A total of 74 neonates were analyzed for eligibility into the study. Fourteenwere excluded due to various reasons depicted in figure. Out of 60 neonates who were eligible and reached $100 \mathrm{ml} / \mathrm{kg} /$ day of feeds, 30 were designated in thefortification group and 30 were in the control group. Baseline characteristics are shown in table-I. Gender distribution was $18(60 \%)$ female and $12(40 \%)$ male in theintervention group, and $14(46.7 \%)$ female and $16(53.3 \%)$ male in thecontrol group.

In the fortification group, mean gestational age was $32 \pm 1.94$ weeks and $31.60 \pm 1.83$ weeks in the control group (table-I).

In the fortification group, mean weight was $1304.66 \pm 113.32$ grams at birth and increased to 1772.33 \pm 250.14 grams at the time of discharge from NICU. In the control group mean weight was $1255.66 \pm 159.43$ grams at birth and increased to $1574.16 \pm 161.60$ grams by the time of discharge from the NICU (table-I). 


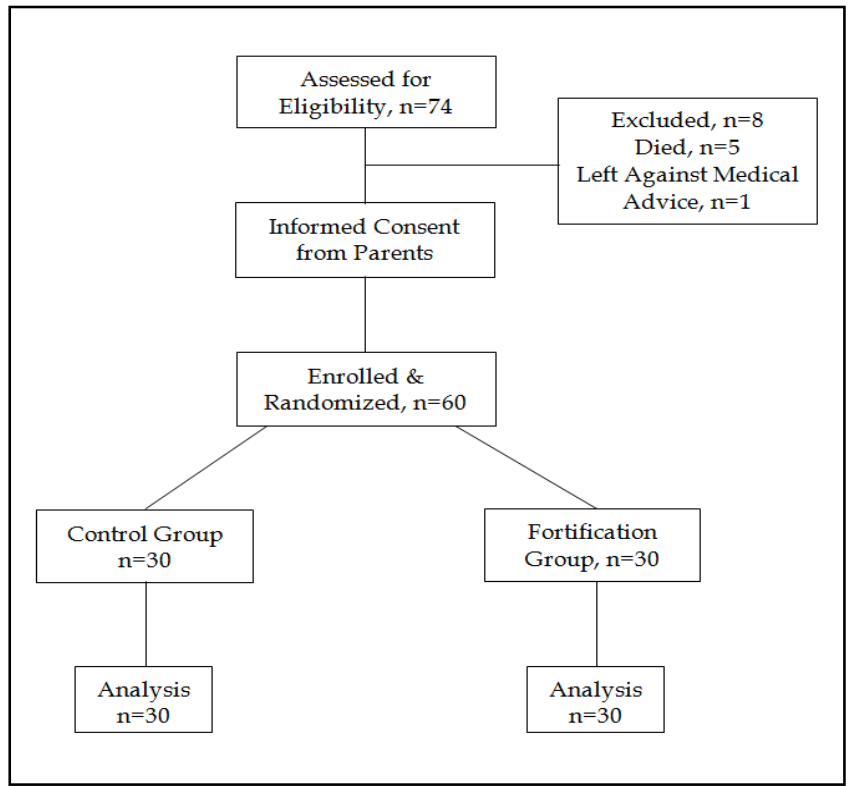

Figure: Patient flow diagram.

Total weight gain was $493 \pm 294.16$ grams in the fortification group and $329.16 \pm 153.90$ grams in the control group with a $p$-value 0.009 (table-II). Weight gained in grams/day was significantly higher in the fortification group $24.83 \pm 5.63$ as compared to the control group $11.72 \pm 3.95$ with $p$-values $0.009 \& 0.001$ (table-II).

Mean length of hospital stay in the fortification group was $20.57 \pm 16.511$ days and $27.67 \pm 8.89$ days in the control group. There was a significant decrease in duration of hospitalization $(p=0.043)$ in the fortification group (table-II). Growth in length and head circumference was observed more in babies in thefortification group but the difference was not statistically significant.

No significant adverse effects were observed in both groups.

\section{DISCUSSION}

There are an estimated 135 million live births Worldwide, $11.11 \%$ babies are born preterm every year ${ }^{5}$. With improving expertise in the field of neonatal medicine increasing number of these babies survive. Most of these neonates suffer from extra uterine growth restrictionand one of the key factors is under nutrition ${ }^{11}$. Premature breast milk provides approximately $60 \mathrm{kcal}, 2.2$ grams of proteins and 2.6 grams of fats per $100 \mathrm{ml}$ of milk, whichis not enough for the optimal growth of these infants ${ }^{12}$. Many different nutritional strategies have been adopted like standard vs targeted fortification, slow vs rapid enteral feed, use of edible oils in feed and even massage therapies with MCT oil to achieve the optimal weight gain ${ }^{13-15}$. Our study demonstrates that the addition of skimmed milk and olive oil to breast milk was beneficial to VLBW neonates, resulting in a statistically significant increase

Table-I: Baseline characteristics of the fortification and the control groups.

\begin{tabular}{|c|c|c|c|}
\hline & Fortification Group (30) & ControlGroup (30) & $p$-value \\
\hline Gestational Age (weeks) & $32 \pm 1.94$ & $31.60 \pm 1.83$ & 0.416 \\
\hline Weight at Birth (grams) & $1304.66 \pm 113.32$ & $1255.67 \pm 159.43$ & 0.175 \\
\hline Weight at Discharge (grams) & $1772.33 \pm 250.14 \mathrm{~g}$ & $1574.16 \pm 161.60$ & 0.001 \\
\hline Birth Length $(\mathrm{cm})$ & $39.70 \pm 1.44$ & $39.20 \pm 1.29$ & 0.163 \\
\hline Discharge Length $(\mathrm{cm})$ & $42.50 \pm 1.68$ & $42.83 \pm 1.37$ & 0.402 \\
\hline Birth fronto-occipital circumference $(\mathrm{cm})$ & $28.46 \pm 1.30$ & $28.43 \pm 1.35$ & 0.932 \\
\hline Dischargefronto-occipital circumference $(\mathrm{cm})$ & $30.46 \pm 1.50$ & $30.93 \pm 1.38$ & 0.216 \\
\hline Mechanical Ventilation & $3(10 \%)$ & $4(13 \%)$ & 0.688 \\
\hline Continuous positive airway pressure & $7(23 \%)$ & $5(16 \%)$ & 0.519 \\
\hline \multicolumn{4}{|l|}{ Table-II: Primary and secondary outcomes. } \\
\hline & Fortification Group (30) & Control Group (30) & $p$-value \\
\hline \multicolumn{4}{|l|}{ Primary Outcome } \\
\hline Total Weight Gain (gms) & $493 \pm 294.16$ & $329.16 \pm 153.90$ & 0.009 \\
\hline Weight Gain (g/day) & $24.83 \pm 5.63$ & $11.72 \pm 3.95$ & 0.001 \\
\hline Length $(\mathrm{cm} / \mathrm{wk})$ & $0.97 \pm 0.22$ & $0.88 \pm 0.17$ & 0.101 \\
\hline Fronto-occipital circumference (cm/wk) & $0.63 \pm 0.11$ & $0.58 \pm 0.11$ & 0.159 \\
\hline \multicolumn{4}{|l|}{ Secondary Outcome } \\
\hline Length of Hospital Stay (days) & $20.57 \pm 16.511$ & $27.67 \pm 8.89$ & 0.043 \\
\hline Blood Urea Nitrogen $(\mathrm{mmol} / \mathrm{l})$ & $4.62 \pm 0.84$ & $4.79 \pm 0.85$ & 0.452 \\
\hline Creatinine $(\mu \mathrm{mol} / \mathrm{l})$ & $76.33 \pm 11.29$ & $77.20 \pm 10.84$ & 0.763 \\
\hline Feed Intolerance (ml) & $5(16 \%)$ & $6(20 \%)$ & 0.739 \\
\hline
\end{tabular}


in weight gain. Further, our study demonstrated that the duration of hospitalization was also statistically less in the fortification group.

Arslanoglu et al, in 2019 concluded in their study that human breast milk is the best nutrient for preterm infants granting health benefits including protection from problems the neonates face in NICU. Therefore human breast milk is the best choice in preterm feeding. They also concluded that unfortified human breast milk does not provide enough nutrients to preterm neonates so fortification of human breast milk is very important ${ }^{13}$.

Mukhopadhyay et al, in 2007 also concluded that preterm very low birth weight infants manifest better growth with human milk fortification ${ }^{16}$.

Edible oils have been used in various studies to fortify breast milk to provide adequate nutrition to VLBW neonates. Olive oil has been added successfully in a study byAmini et al, in 2011. They found in their study of 50 cases (25 in each group) that neonates in the fortification group gained more weight $280.49 \pm$ $27.20 \mathrm{~g}$ than neonates in the control group $117.63 \pm$ 40.126 g receiving only human milk ( $p$-value 0.0004 ) with decrease in length of hospitalization ( $p$-value $0.003)^{17}$. Similarly, Vaida et al, used coconut oil as the fortifier to expressed breast milk to augment weight gain. The results showed increased weight gain in the fortified group vs the control group $(19.47 \pm 8.57 \mathrm{~g} /$ day vs $11.59 \pm 5.33 \mathrm{~g} /$ days) ${ }^{18}$. These findings were supported by results of study conducted by Blas et al. Mantaring III in Phillipines. They also used virgin coconut oil in 90 neonates with VLBW and observed increased trend in all the growth parameters with decrease in adverse effects like sepsis and feed intolerance ${ }^{19}$.

Recently, Sumitha et al, conducted a randomized control trial on 60 babies to evaluate weight gain by using coconut oil as a breast milk fortifier. Contrary to findings of other studiesthey could not find significant increase in any of the growth parameters ${ }^{20}$.

Besides calories, VLBW neonates have an increased requirement of proteins. These requirements are met in NICUs in the form of proteins in parenteral nutrition and in the form of human milk fortifiers. Embleton et al, in a recent review have summarized key studies with addition of proteins to fortify enteral feeds. Although techniques used were different in the various studies, they concluded that protein fortification of breast milk is essential for optimal growth and braindevelopment of preterm neonates ${ }^{21}$.
Increased demand of proteins by VLBW preterm sometimes cannot be met with standard fortification because of individual variation of nutrition in breast milk and sub optimal levels of proteins in fortifiers beingused. Picaud et al, in their recent retrospective study concluded that VLBW preterm infants needed extra supplementation of proteins to their standard fortification to achieve satisfactory growth ${ }^{22}$.

Importance of high protein intake is also established in a study by Cormack et al, they evaluated the difference between high protein intake vs low protein in first 30 days of life resulting in better growth velocities for weight gain, head circumference and length in the high protein group ${ }^{23}$.

We sought to use readily available, practical and cheap fortification by using skimmed milk as a fortifier for proteins and olive oil as a source of extra calories. In the literature we could not find any study where both skimmed milk and olive oil have been used together as means of fortification of EBM to gain weight in VLBW neonates. This would be the firstreport from our country conducted so far to evaluate results of fortification of expressed milk with edible oil and protein.

A limitation of our study was that the neonates were not classified into SGA and IUGR. In our resource poor setting, many of the patients do not have appropriate prenatal care, and the prerequisite antenatal ultrasounds were not available for SGA and IUGR differentiation.

\section{CONCLUSION}

Fortification of human breast milk with olive oil and skimmed milk improves the weight gain of neonates and reduces length of hospital stay. This is a very useful finding for a resource poor setting, like Pakistan, where this could prove to be an affordable means of fortifying breast milk.

\section{CONFLICT OF INTEREST}

This study has no conflict of interest to be declared by any author.

\section{REFERENCES}

1. Hughes MM, Black RE, Katz J. 2500-g low birth weight cutoff: history and implications for future research and policy. Matern Child Health J 2017; 21(2): 283-89.

2. Blencowe H, Krasevec J, Onis M de, Black RE, An X, Stevens GA, et al. National, regional, and worldwide estimates of low birth weight in 2015, with trends from 2000: a systematic analysis. Lancet Glob Health 2019; 7(7): 849-60.

3. National Institute of population Studies. Demographic and Health Survey, Pakistan 2017-18. Islamabad 2017-2018 [Internet] 
Available at: https://dhsprogram.com/pubs/pdf/FR354/ FR354.pdf (Assessed at: Feb 19, 2020)

4. Hussain S, Ahmed S, Tarar S, Tasleem G. Low birth weight: frequency, demographic profile and association with maternal risk factors at a tertiary care teaching hospital. Pak Armed Forces Med J 2018; 68(4): 850-55.

5. World Health Organization. Care of the premature and lowbirth-weight newborn 2018. [Internet] Available from: http:// www.who.int/maternal_child_adolescent/newborns/. (Assessed at: Feb 19, 2020)

6. Armanian AM, Barekatain B, Sohrabi F, Salehimehr N, Mansourian $\mathrm{M}$. The prevalence of complications of prematurity among 1000 newborns in Isfahan, Iran. Adv Biomed Res 2019; 8(1): 1215.

7. Markopoulou P, Papanikolaou E, Analytis A, Zoumakis E, Siahanidou T. Preterm birth as a risk factor for metabolic syndrome and cardiovascular disease in adult life: a systematic review and meta-analysis. J Pediatr 2019; 210(): 69-80.

8. Kumar RK, Singhal A, Vaidya U, Banerjee S, Anwar F, Rao S. Optimizing nutrition in preterm low birth weight infants consensus summary. Front Nutr 2017; 4(1): 20-23.

9. Cortez J, Makker K, Kraemer DF, Neu J, Sharma R, Hudak ML. Maternal milk feedings reduce sepsis, necrotizing enterocolitis and improve outcomes of premature infants. J Perinatol 2018; 38(1): 71-74.

10. Agostoni C, Buonocore G, Carnielli VP, De Curtis M, Darmaun D, Decsi T, et al. Enteral nutrient supply for preterm infants: commentary from the European Society of Paediatric Gastroenterology, Hepatology and Nutrition Committee on Nutrition. J Pediatr Gastroenterol Nutr 2010; 50(1): 85-91.

11. Avila-Alvarez A, Solar Boga A, Bermúdez-Hormigo C, Fuentes Carballal J. Extrauterine growth restriction among neonates with a birthweight less than 1500 grams. An Pediatr (English Edition). 2018; 89(6): 325-32.

12. Gidrewicz DA, Fenton TR. A systematic review and metaanalysis of the nutrient content of preterm and term breast milk. BMC Pediatr 2014; 14(1): 216-18.

13. Arslanoglu S, Boquien CY, King C, Lamireau D, Tonetto P,
Barnett D, et al. Fortification of human milk for preterm infants: update and recommendations of the european milk bank association (EMBA) working group on human milk fortification. Front Pediatr 2019; 7(): 76-80.

14. Kadam RM, Prasad VSV, Santosh M. Rapid versus slow advancement of feeds in preterm babies less than 34 weeks in incidence of NEC and feed intolerance. J Neonatal Biol 2016; 5(1): 214-18.

15. Jabraeile M, Rasooly AS, Farshi MR, Malakouti J. Effect of olive oil massage on weight gain in preterm infants: A randomized controlled clinical trial. Niger Med J 2016; 57(3): 160-63.

16. Mukhopadhyay K, Narang A, Mahajan R. Effect of human milk fortification in appropriate for gestation and small for gestation preterm babies: a randomized controlled trial. Ind Pediat 2007; 44(4): 286-90.

17. Amini E, Shariat M, Nayeri F, Nili F, Ebrahim B, Dalili H. A randomized controlled clinical trial of olive oil added to human breast milk for weight gaining in very low birth weight infants. J Fam Reprod Health 2011; 5(3): 73-77.

18. Vaidya UV, Hegde VM, Bhave SA, Pandit AN. "Vegetable oil fortified feeds in the nutrition of very low birth weight babies" Ind Ped 1992; 29(12): 1519-27.

19. Mantaring JV, Amante-Aurelio M. R.A randomized controlled trial on the use of virgin coconut oil in augmenting weight gain among infants weighing 1500 grams or less: Preliminary results. Philippine J Pediat 2005; 54(4): 223-19.

20. Arun S, Kumar M, Paul T, Thomas N, Mathai S, Rebekah G, et al. An open-label randomized controlled trial to compare weight gain of very low birth weight babies with or without addition of coconut oil to breast milk. J Trop Pediatr 2019; 65(1): 63-70.

21. Embleton ND, van den Akker CHP. Protein intakes to optimize outcomes for preterm infants. Semin Perinatol 2019; 43(7): 151-54.

22. Picaud JC, Houeto N, Buffin R, Loys CM, Godbert I, Haýs S. Additional protein fortification is necessary in extremely lowbirth-weight infants fed human milk. J Pediatr Gastroenterol Nutr 2016; 63(1): 103-105.

23. Cormack BE, Bloomfield $\mathrm{FH}$. Increased protein intake decreases postnatal growth faltering in ELBW babies. Arch Dis Child Fetal Neonatal Ed 2013; 98(5): F399-404. 